\title{
Monitoring Disability Policies and Legislation towards Effective Exercise of Rights to Equality and Inclusive Access for Persons with Disabilities: The Case of the Quebec Model
}

\author{
Patrick Fougeyrollas * (D) and Yan Grenier \\ CIRRIS, Department of Anthropology, Laval University, Quebec City G1M 2S8, QC, Canada; \\ yan.grenier1@gmail.com \\ * Correspondence: patrick.fougeyrollas@cirris.ulaval.ca; Tel.: +1-418-455-4055
}

Received: 5 May 2018; Accepted: 8 June 2018; Published: 12 June 2018

\begin{abstract}
Quebec's government established a mechanism to monitor its progress towards achieving the right to equality for people with disabilities. With the goal of strengthening the accountability of public actors, this mechanism is based on legal provisions and inclusive political guidelines. In 2009, the provincial government adopted a policy entitled "Equals in Every Respect: Because Rights Are Meant to Be Exercised" along with other legal dispositions aimed at significantly increasing the social participation of people with disabilities. The Disability Creation Process, a conceptual reference model also known as the Quebec Model, proposes that public actors should be able to identify and act upon environmental obstacles within their respective competences to transform them into facilitators. The challenge facing inclusive policy-monitoring mechanisms is to acquire quantitative and qualitative information-collecting tools and strategies that link the quality of access of the components of the physical and social environment to the quality of the social participation for the various segments of the population with or without disabilities.
\end{abstract}

Keywords: disability; human rights; policy monitoring; classification; disability creation process; CRPD

\section{Introduction}

The Disability Creation Model (DCP) is useful in defining disability as situational and as a phenomenon resulting from the interaction of a person with disabilities with an inadequate environment. It contributed to producing methodological elements for state interventions in the domain of disability and monitoring the progress of state initiatives regarding the reduction of obstacles. Methodologically, this paper retraces the genealogy of the DCP's development in relation to the transformations of the provincial state of Quebec regarding health and social legislations and policies linked to disability. ${ }^{1}$ Additionally, this paper revisits the DCP's historical context, development, and conceptual contribution at the international level in the recognition of environmental factors. At the national and sub-national levels, this paper shows that the DCP facilitated the introduction of measures aimed at ensuring the full social participation of persons with disabilities, as well as

1 The methodology used in this article includes a restrospective analysis of Quebec's laws and policies, of the normative development at the international level regarding disability, and an analysis of the links between their respective developments. Legislative and policy documents were the main sources of information for this research. Lastly, one of the authors has been involved in the processes described for over forty years. His presence through an anthropological engagement facilitated the description of the events and their details. 
the unhindered exercise of their right to equality. Developed in accordance with Quebec's disability policy, the DCP led to scientific applications, to the harmonization of policies and services in reference to a robust conceptual framework, and to a renewed and non-medical understanding of disability. Finally, this paper demonstrates how the DCP is a useful framework for assuring the compatibility between state laws and policies with the normative content of the international Convention on the Rights of People with Disabilities (CRPD).

\section{Historical Context}

In the late 1970s, Quebec, just as the rest of the West, witnessed the emergence of a new social movement aimed at promoting and defending the rights of a population with disabilities so far invisibilized, minorized, and without access to a medium of expression. They were rendered invisible since persons with disabilities were generally institutionalized, locked or hidden within families. These individuals were considered abnormal or deviant because of their bodies, their features or behaviors, and were placed out of sight, hidden from view or erased socially since it was believed they would generate fear, avoidance or even guilt and shame on the part of the collective. They were subject to stigma and treated as sub-humans. Generally described by negative categories such as "cripples", "idiots", "fools" or "invalids", they were considered unemployable and objects of Christian charity, philanthropy, and from the 1960s, beneficiaries of state aid and support programs.

Irresponsibility, which is a key element for admittance into asylum care, marked persons with disabilities unlike other marginalized categories such as the "lazy deviants", the "homeless", the "dishonest", and the "criminal", who were judged responsible for their condition by society and separated from honest people through carceral measures.

However, the fate of one or the other was no different. They were subject to disciplinary rules, put to work through mandatory so-called occupational work, lived miserable daily life regimes, and were subjected to neglect and denial of their dignity. People with disabilities were without a voice and without political leverage [1].

It was not until the late 19th and early 20th century that classificatory efforts aimed at population management and policy implementation and monitoring were designed and put to use. These efforts were first linked to concerns regarding epidemiological public hygiene and the need for statistics on causes of death in large urban areas. It is a little-known fact that the origin of The International Classification of Diseases [2] is anchored in the fight against epidemics resulting from industrialization, population displacements from wars and conflicts, from a lack of sanitation, and poverty, promiscuity, and food shortage in cities. The development of a standardized medical language and the individualization of sickness and infirmity accompanied the gradual accuracy of diagnosis, and closely followed the growth of medical knowledge, infection control, and development of therapeutic pharmaceutical arsenals. This allowed, along with major public health reforms, to gradually reduce mortality and to improve the survival of people with chronic medical conditions or sequelae of trauma and injuries which resulted in persistent functional or behavioral negative consequences.

These considerations are useful to identify the development of disability that is historically built upon statistical monitoring, through which progress was measured by a quantitative reduction in mortality and by analyzing the evolution of morbidity rates according to diagnostic categorizations. The variation in size of these categories provided progress indicators of interventions on the living conditions of populations [3]. Dominated by the requirement of reproduction and preservation of the workforce, medicine served as one of the strong arms of productivism and as reparation for victims of war. Social forces of the time were the pharmaceutical industry, biomedical research, vocational and social rehabilitation, as well as producers of appropriate technologies dedicated to socially valued and deserving invalid persons under the responsibility of the state. They were at the source of the development of medical knowledge and the power of its institutions. Under this healthcare regime, forms of insurances and services were mainly developed for amputees and wounded veterans, as well as for injured workers. For civilian cripples for whom the causes of impairments were due to diseases, 
genetic conditions, acts of God or difficult socio-economic conditions, they only benefited from these advances after World War II. More significantly, health services programs were implemented during and after the 1960s and 1970s. Additionally, the democratization of access to education played an important role for people with motor, sensory, intellectual disabilities, and disabilities related to mental health problems $[4,5]$.

\section{Quebec's Quiet Revolution: The Birth of the Welfare State}

Before the 1960s, the federal government of Canada was the main developer and provider of providential initiatives. After the adoption of the Canada Assistance Plan in 1966 and of the Medical Care Act in 1968, cost sharing between the federal and provincial governments for medical insurance plans were implemented. Within the Canadian Confederation, provinces have exclusive jurisdictions over health, social services, and education. This led Quebec's provincial government, after two waves of reforms in the 1960s, to implement in 1969 its own health and welfare policies in line with the federal laws and policies, thus making disability a provincial affair. The subsequent developments of social and health services, including rehabilitation, differed from one province to another, with each having their own particularities as well as health and disability frameworks.

In 1971, the Castonguay-Nepveu Quebec Government Commission "discovered" the "disabled" were largely symbolized by their exclusion from the labor market [6]. The commission was the first step in the deinstitutionalization process which was inspired by the Scandinavian principle of normalization and the denunciation of institutional environments which stigmatized and deprived residents of their most basic human rights [7]. The process required a clinical ordering and the distinction of populations between physical disabilities from intellectual disabilities, which were still confused with psychiatric problems. Distinct networks of aid and support were nationalized for these various populations, previously served by religious communities. During the Quiet Revolution in Quebec, social, educational, and professional integration policies for the "disabled" were implemented.

\section{A Paradigm Shift: From Protection to Rights}

In 1975, the UN adopted the Declaration on the Rights of Persons with Disabilities [8]. Simultaneously, Quebec introduced, from a welfare perspective, a first bill proposal on the protection of disabled people. This proposal triggered the mobilization of a new social movement of people with disabilities. In Quebec, this movement brought together representatives of all groups of people with disabilities and especially young people who demanded that society stop considering them as minorized beings and pleaded for the end of supportive measures given by medical experts in segregated spaces and institutions. This was in agreement with the British, Scandinavian, and North American normalization [7], social roles valorization [9], and independent living [10,11] movements which argued that people with disabilities are people with equal rights as the rest of humanity.

In 1978, in agreement with the UN's Declaration, the Act to Secure Handicapped Persons in the Exercise of Their Rights was adopted by a unanimous vote by the National Assembly of Quebec. While establishing an inter-sectoral perspective away from health and social protection, the Act put in place measures aimed at the professional, social, and educational integration of people with disabilities regardless of their age $[12,13]$.

This Act also created the Office of Disabled People of Québec (OPHQ), whose cross-sectoral mandate served to coordinate the actions of all ministries and government agencies down to municipalities. This organization with its public and community partners gradually led to the creation of what would later be known as the Quebec model. It benefited from favorable conditions following the enactment by the UN in 1980, of the International Year of Disabled Persons. During this period, the OPHQ launched an extensive operation entitled "Towards an Overall Policy" which required the assessment of the living conditions of disabled people in the whole territory.

For this purpose, a small OPHQ research team, in which participated Patrick Fougeyrollas, conducted a comprehensive action research. The team immediately faced three major questions: What 
is a disabled person? What are the boundaries of this new social group? How to consider the challenge of improving their human rights? At the time, none of these questions were answered and everything was to be done. First, a literature review and networking with experts at the international level allowed them to understand the importance of classifications within the domain of Health [14].

The World Health Organization (WHO), newly created in 1948, took under its responsibility the International Classification of Diseases (ICD). This was the 6th edition of this harmonization tool of medical diagnoses resulting from the pioneering work of public hygiene statisticians. In the early 1970s, a major finding was made by WHO physicians. Data on causes of death are insufficient to understand the exponential phenomenon of chronic disease and disability conditions with people living longer lives, thus reducing mortality rates. The need to define a new health paradigm to understand the well-being and quality of life of people while preventing aggravation of their disabilities was required.

New domains of medicine such as physical rehabilitation and psychiatry for people living with the consequences of long-term diseases, injuries, and other disorders have been developed. This was mainly due to the consequences of war, epidemics such as poliomyelitis, and socio-economic development programs supporting work integration of disabled veterans and civilians. New health indicators became essential to feed the information systems used to plan appropriate responses and monitor their efficiency. Dr Nagi, a sociologist and physician was a pioneer in United States in distinguishing the medical field on impairments from the rehabilitation field on function limitations and disabilities related to social integration $[15,16]$.

Mandated by the WHO and inspired by Nagi's work, Dr Philip Wood, an English rheumatologist and epidemiologist, submitted in 1976 an additional classification to the ICD during the General Assembly of the WHO $[17,18]$. This new classification related to the consequences of diseases and injuries was the subject of controversy and led to many discussions between medical specialties. A revised version was published on an experimental basis in 1980 under the name of the International Classification of Impairments, Disabilities, and Handicaps (ICIDH) [19]. It is through the first international scientific articles on this subject and the awareness of Quebec experts of these developments, such as Maryke Muller, Mario Bolduc, Dr Louis Bernard, and the anthropologist Pierre Joubert that the OPHQ's research team acquired a new understanding of disability [20-22]. Indeed, this experimental classification allowed one to distinguish impairments such as organ damage from disabilities as human activity limitations. It also allowed for the innovative consideration of the concept of handicap as social disadvantages experienced by people with chronic disabilities [23,24].

These conceptual developments enriched the literature produced by social movements such as those of normalization and independent living, which advocated for social transformations aimed at removing obstacles to the exercise of rights of people with disabilities. This became the basis of the action research's theoretical framework which culminated in 1984 with the publication of the policy On Equal Terms: The Social Integration of Handicapped Persons, a Challenge for Everyone by the OPHQ [25].

Through this policy, the OPHQ provided this methodological tool to its collaborators so that inter-sectoral coordination would be carried out in a spirit of harmonization of governmental orientations and services. The policy served to rationalize resources in regard to the persons and their particular roles in the decision-making process. Additionally, the policy was the result of an extensive exchange between administrators and disabled citizens. Suppliers of services have found in this work a planning and decision-making tool [25].

This theoretical framework allowed one to link the intervention on the causes of illness and injuries with prevention measures, intervention on "impairments" with medical treatments, interventions on "disability" with rehabilitation treatments, and finally the intervention on "handicap" or social disadvantages linked to disability with all laws, policies, and programs, and social representations to remove barriers to social integration. In agreement with the social model of disability [26], which also emerged around the same time, the On Equal Terms model considered that disability is fundamentally social and not an individual problem, as it is caused by material, social, and behavioral (social representations) environmental living conditions. 


\section{In Recognition of a New Definition of Disability Based on the Interaction between Personal Factors and Environmental Factors on Social Participation and Rights: Thirty Years of Struggles}

An international meeting on the ICIDH was held in Quebec City in 1987. It brought together major institutional stakeholders as well as experts on the conceptualization of disability. In this historic meeting, different organizations' representatives participated, such as Disabled Peoples' International (DPI), the UN, the WHO, the Council of Europe, and the Canadian and Quebec governments, as well as individual participants, including Dr. Philip Wood and pioneering experts like Dr. Pierre Minaire, Dr. Claude Hamonet, Marijke De Klein, and Elysabeth Badley [22]. It was during this meeting that the foundation of the WHO's Collaborating Centers on ICIDH were established in France, the Netherlands, and North America. Until 2001, these centers would orchestrate with Geneva on the revision of the ICIDH, which resulted in the publication of the International Classification of Functioning, Disability and Health (ICF) $[23,27]$.

The 1987 meeting organized by the OPHQ and the Quebec Committee on ICIDH (QCICIDH) - an NGO founded by three disability rights activists (Mario Bolduc, Marike Muller, and Author 1) -was motivated by the emergence of a social approach to disability and a clarification of the definitions that have emerged since the early 1980s [25]. This event highlighted the need for a critical analysis of medical or individual understandings of disability as inherent components of the person and the urgent need for inclusion in the analysis of all sectors of society which were then called "environmental factors". These later played a fundamental role in the implementation of the conditions of social integration and effective exercise of human rights by people with disabilities.

Largely unknown in the literature, it was during this meeting that the QCICIDH and the OPHQ were mandated to propose a revision of the concept of "handicap" — defined as social disadvantage in the ICIDH and its components. This mandate was realized by the QCICIDH's research team, with main financial support from the OPHQ and Quebec's Social Affairs Department over the next ten years. It led to the development, through multiple international consultations with concerned stakeholders including disability rights movement, of the Quebec Classification on Disability Creation Process (DCP) [23,28-30]. The Quebec Team participated at the annual WHO meetings, and with persistence struggled for the recognition of social and physical contextual determinants of disability. With the support of Disabled Peoples' International led by Canadian Henry Enns and progressive North American stakeholders as David Gray, Harlan Hahn, Jerome Bickenbach, Gale Whiteneck, and Scott Brown, the WHO decided in 1995, after long years of resistance, to include a conceptual domain of environmental factors in the successive draft versions of the revised ICIDH [31]. The international influence of the Quebec Disability Creation Process model was strong and especially supported by the French Collaborating Centre on the ICIDH and by French-speaking countries.

In 1995, the QCICIDH was incorporated as a disability rights NGO and named International Network on Disability Creation Process (INDCP). The organization was active in the work of WHO's committees until the publication, in 2001, of the ICF [27]. Despite a number of similarities between the ICF and the DCP, particularly the inclusion of identity factors (called personal factors in the ICF) and environmental factors in the construction of disability, differences remained between the two models [32]. The most important being the choice on the part of the ICF to not define as mutually exclusive the concepts of activity and of participation along with their related taxonomies. This choice was not compatible with the concepts of capability and life habits of the DCP that distinguishes clearly and as mutually exclusive the disabilities belonging to the person and disabling situations. In this perspective, disabling situations are the results of the interaction process between elements belonging to the person (i.e., identity, organic systems, capabilities) and that which belong to her environment (i.e., physical and social environmental factors) $[23,33-36]$ in the achievement of life habits.

This choice of the conceptual segmentation within the Quebec conceptual model was rooted in the political will to make it impossible to attribute the responsibility of disability to the person or inversely, situations of social participation without the mandatory consideration of environmental factors. This briefly explained why the DCP was officially adopted by the Government of Quebec. It was done 
with the support of the community and the disability rights advocacy movement. The adoption of the DCP was part of the legal and political framework put in place to help articulate its implementation. Finally, the DCP is used to assess the increase of social participation and the right to equality of Quebecers with disabilities.

\subsection{Legislative Strengthening of the Accountability of Quebec Actors}

The Act to Secure "Handicapped" Persons in the Exercise of their Rights with a View to Achieving Social, School, and Workplace Integration (2005) was a revision of the earlier Act of 1978 which marked the recognition of the rights of disabled people, but it went further and provided the OPHQ with more proactive legislative tools to remove obstacles to social participation $[12,13]$.

A definition of "disabled person" consistent with the DCP had also been adopted through a concertation with the autonomous disability rights advocacy community movement.

It meant "a person with an impairment causing a significant and persistent disability, who is liable to encounter barriers in performing everyday activities" (section1G) [13]. This definition applied to any person, man or woman, with impairments and disabilities. It could be a child, an adult or elder person. It concerned both the disabilities related to anatomical impairments or organ functions, autism spectrum disorders or severe mental health problems, but ignored the circumstances of their occurrence. The scope of the definition, therefore, included elder people with disabilities related to aging. The definition also allowed for the inclusion of people with episodic or cyclical significant disabilities [37].

The definition referred to the potential disabling situations encountered when a person with disabilities faced environmental barriers to achieving daily activities. This didn't mean that every person with impairments and significant and persistent disabilities would face barriers that would lead them to experience disabling situations. In the sense of the law, these people were still considered to be disabled people. This point was very important to understand and was consistent with a situational approach to disability. Indeed, it was possible for environmental facilitators related to access to compensation measures, to accessible environments, to nondiscriminatory social representations, and to allow the achievement of life habits such as daily activities and social roles. However, it was understood that if such assistive devices, human support, accommodations, equipment, financial resources, etc. were no longer available as a result of a restriction in access to home support services or no longer met the functional evolution of the person, then disabling situations would occur [37]. This recognition was utterly important because it indicated that even when the person achieved her life habits according to her choices and to her satisfaction, the quality of her social participation remained potentially vulnerable without continued vigilance of public, private, and community social actors to ensure the quality of access to the needed resources, services or aids. It clarified the responsibility of actors to ensure the availability, accessibility, affordability, social acceptability, and usability of these physical and social facilitators. This is entirely consistent with the DCP (Figure 1), which showed that the effective exercise of rights of people with bodily and functionality differences depended on the quality of access of the living environments for these people [38]. It appeared essential to better understand the concept of disabling situations as a measure of the quality of social participation or of the exercise of human rights. For example, one could experience a disabling situation in school activities and not in other relational or leisure activities. Finally, the DCP stated that it was incorrect to qualify a disabling situation as physical, mental, intellectual, visual or hearing since it reactivated individualized or biomedical ideas of disability. 

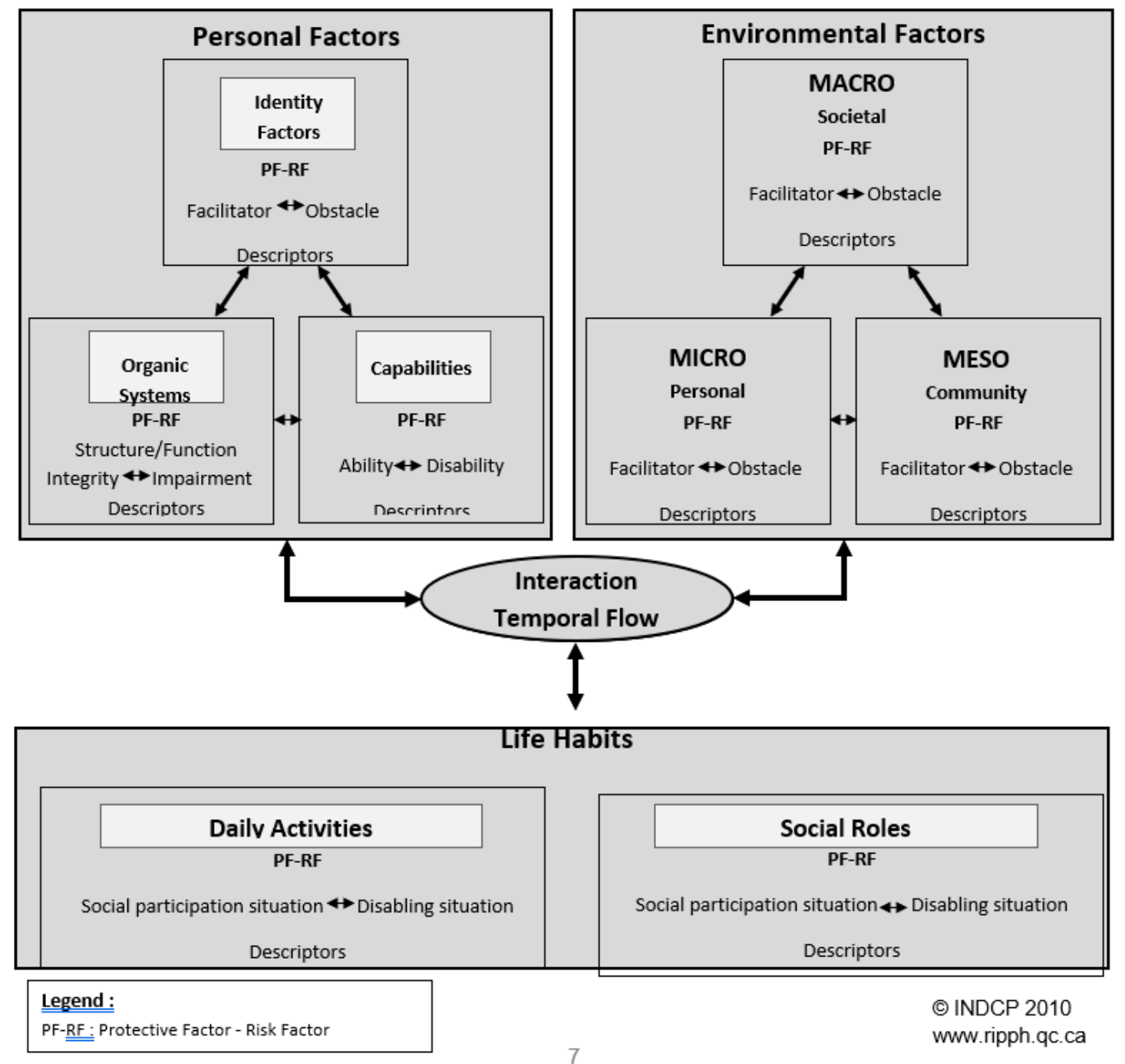

Figure 1. Human Development Model and Disability Creation Process (DCP v.2).

\subsection{The Legal Entrenchment of the Fundamental Orientations of on Equal Terms: Always Forward Thinking}

These policy directions found under Article 1.2 of the Act [13] served to guide the OPHQ, government departments, and their services networks, municipalities, and public and private agencies:

(a) adopting an approach that views the disabled person as a whole, respects individual characteristics, and facilitates the increased development of capacities;

(b) facilitating the autonomy of disabled persons and their participation in individual or collective decisions that concern them and in managing the services offered to them;

(c) giving priority to resources and services that enable disabled persons to remain in or return to their natural living environments;

(d) facilitating the adaptation of the built environment to the needs of disabled persons and their families without discrimination or privilege, the regional self-sufficiency of resources, and the effective linking of local, regional, and Quebec-wide resources;

(e) fostering continuing coordination for the management and complementarity of resources as well as the permanence and maximum integration of services;

(f) achieving a decent quality of life for disabled persons and their families, full social integration of disabled persons and maximum protection against risk factors for impairment. 
The international Convention on the Rights of Persons with Disabilities was a victory for the international disability alliance, but a challenge for monitoring its implementation. For the first time, leaders of international disability rights NGOs and representatives of all types of disabilities formed an alliance, the "International Disability Alliance" (IDA), and were fully participating with the task force preparing the text of the UN Convention on the Rights of Persons with Disabilities (CRPD) adopted in 2006 [39]. One of the many crucial issues was to get a consensus on a definition of disability.

Recognizing that disability is an evolving concept and that disability results from the interaction between persons with impairments and attitudinal and environmental barriers that hinder their full and effective participation in society on an equal basis with others (art e).

Avoiding any ambiguity, this definition is fully coherent with a social approach to disability and recognized that disability was evolving as a temporal construct and an interactive systemic process. As the DCP conceptual model, it states that disability was a result of the interaction between personal factors and environmental factors. They both are possibly influencing the full and effective social participation and exercise of equality of human rights with others. As we explained before, this definition recognizes the importance of bodily and functional capacities but emphasizes the fact that full exercise of human rights is possible for all if attitudinal and environmental barriers are removed and replaced with facilitators.

The compatibility between conceptual definitions of disability between the CRPD and the Quebec conceptual model was of crucial importance for the Quebec Government, OPHQ, and INDCP. Building on more than 20 years of experiments with policies anchored in the paradigm of autonomy, respect of integrity and differences, and equality of rights for all, INDCP pursued the project not only to go on the development of a methodology for monitoring the implementation and assessment of outcomes of Quebec's policy. As researchers in the field of Disability, we worked toward the goal of a significant methodological contribution for the monitoring of the CRPD and other national, regional or municipal policies in the field of equality of rights of people with disabilities and their families.

\section{Equals in Every Respect: For a Real Exercise of the Right to Equality}

The legislative guidelines explained above, coherent with the fundamental principles of the CRPD, were reinforced by the adoption in 2009 by the Quebec Government of a new policy as advocated by the Act [13] - the policy Equal in Every Respect [40]. Contrary the federal position using the ICF as its reference framework, the Quebec policy was officially based on the conceptual model of the DCP and fulfilled a legal duty of the OPHQ to promote a standardized classification in the field of disability (art. d1). This choice was justified by the critical distance taken by the DCP from the persisting biomedical and health contents of the ICF. Careful attention to the terminology used by the OPHQ in the policy and implementation documents was explicit and was seeking to harmonize the language used by Quebec social actors and strengthen their accountability within their activity sector to act on environmental factors.

The expected outcomes of the policy were improving the living conditions of disabled people, completely meeting their basic needs, and ensuring equality with other citizens in the exercise of their social roles. Because of its transversal orientations, the policy was able to address economic, cultural, and social rights in all domains of society. The policy identifies three main challenges for social change coherent with the CRPD's fundamental principles:

(1) an inclusive society that systematically takes account of disabled people and their families from the design stage of any intervention on the physical and social environment;

(2) a unified and more equitable society that addresses the factors associated with poverty: make up for the shortfalls of income and additional costs related to the particular needs of people with disabilities. It also seeks the coordination and complementarity of measures, programs and services. Strengthening of inter-sectoral action is particularly recommended;

(3) a society that respects the choices and needs of disabled people and their families: allow for the participation in decisions that affect them and the availability of structured support services; 
Citizen participation at the heart of individual and collective decisions; preservation of the family environment as the primordial space of integration along with adequate support and preventive measures to avoid institutionalization $[37,40]$.

\section{Mandatory Annual Action Plans for the Reduction of Barriers to Social Participation}

On the 17th of December 2005, each government department or public agency employing at least 50 persons and every local municipality with at least 15,000 inhabitants in Quebec were required to adopt an action plan. These plans were aimed at identifying the barriers to integration disabled persons encounter in the sector of activity of the department or agency, and describing the measures taken over the past year and those to be taken in the coming year to reduce barriers to integration in that sector of activity. The action plan must include any other element determined by the government upon recommendation of the minister, and must be prepared and published annually (Art.61.1 [13]).

For the last 10 years, the OPHQ monitored the annual production of action plans by public actors, with the addition since 2015 of a vast network of health and social services for people with disabilities of all ages. The OPHQ analyzed the compliance of the actions plans, produced annual reports, and every five years reported to the responsible minister who presented outcomes to the National Assembly. Annually, Quebec's government departments and public organizations planned an average of one thousand obstacle reduction measures regarding social participation in their respective areas of responsibility, and municipalities planned more than two thousand [41]. Every five years, a plan of government commitments is produced to monitor the implementation of the policy "Equals in Every Respect", and with regards to the provisions of the law. An implementation monitoring committee of the policy focusing on action plans, which is composed of representatives of key disability rights advocacy organizations and ministries, is consulted regularly by the agents of the OPHQ regarding results and planning procedures for evaluating these same results.

Quebec has established a monitoring mechanism of its progress towards the right to equality based on legal provisions and inclusive policy guidelines to strengthen the accountability, mainly of public actors as the private sector is not subject to the obligation of producing action plans. Adopted in 2009, the policy "Equals in Every Respect" and its political and legal provisions are part of a goal to significantly increase the social participation of people with disabilities over the course of 10 years. The reference model DCP enables us to understand that public actors identify and act on environmental obstacles within their respective areas of competencies to transform them into facilitators.

Annually, the OPHQ devotes efforts to a quantitative analysis of expected results. This compliance analysis focuses on the objectives, deadlines, and the interventions by public actors to reduce environmental obstacles. Though, from the DCP perspective, this is insufficient. A second level of review of the results of action plans would require the documentation of whether these environmental interventions resulted in real improvements of access for users.

What is needed is to precisely identify the impact of these measures on improving the quality of social participation of the population with disabilities in a differentiated manner. This means allowing to take into account the identity characteristics (i.e., gender, age, family status, ethno-cultural and linguistic background, place of residence, education, income, and employment status) of populations, as well as the types and severity of impairments and disabilities, and their modes of acquisition. This would allow for the assessment of the improvement of social participation for each category of the population.

Measuring the quality of social participation and the effective enjoyment of human rights requires periodic quantitative and qualitative population surveys at various territorial levels (i.e., national, regional, and municipal). While efforts were made in Quebec at the turn of the new millennium in producing these surveys, they came to halt because of budget cuts linked to the neo-liberal turn of the state [23]. 


\section{Conclusions}

For the coming years, the great challenge facing implementation and assessment of impacts of inclusive policies will be to develop strategies for quantitative and qualitative information gathering. The DCP requires the documentation of the relationship between the quality of access of the components of the material and social environment, and the achievement of life habits of various segments of the disabled population [42,43]. In addition, measuring the effective exercise of the right to equality requires the comparison of the quality of social participation between population segments that share similar identity factors, with and without impairments and disabilities.

The political challenge that Quebec faces is twofold. One, to fully operationalize a model of social and interactionist understanding of disability. Second, to make it the center of the monitoring and assessment of the impacts of action plans of all public and private actors of its territory. This needs to include, in a practical and collaborative way, modalities of citizenship participation of persons with disabilities and their families as well as their representative organizations. The argument of this paper, focusing on the Quebec Model and its developments, suggests that the implementation of the CRPD [39] will be effective only to the extent that such information systems and monitoring mechanisms implemented in each state party that ratified the convention (177 state parties ratified the convention by 2018) and harmonized it to offer comparable results.

Author Contributions: P.F., anthropologist was directly involved as principal researcher in the successive research projects related to this paper. He is the principal writer. Y.G., anthropologist is co-writer, with expertise in disabilities studies and, policy analysis. He translated the article and made English editing.

Funding: This research received no external funding.

Conflicts of Interest: The authors declare no conflicts of interest

\section{References}

1. Boucher, N.; Fougeyrollas, P.; Grenier, Y. Mémoire, action collective et émancipation dans le champ du handicap. In Inter Reconnaissance, la Mémoire des Droits dans le Milieu Communautaire au Québec; Saillant, F., Lamoureux, E., Eds.; PUL: Quebec City, QC, Canada, 2018; pp. 143-172.

2. World Health Organisation. International Classification of Diseases; WHO: Geneva, Switzerland, 1948.

3. Biraben, J.N. La Classification des handicaps, outil d'analyse et instrument d'action. In Handicaps et Inadaptations-Les Cahiers du CTNERHI, n4; CTNERHI: Paris, France, 1990; pp. 985-988.

4. Bickenbach, J.E. Physical Disability and Social Policy; University of Toronto Press: Toronto, ON, Canada, 1993.

5. Stiker, H.-J. Corps Infirmes et Sociétés; Paris Aubier; New Editions; Dunod: Paris, France, 1982.

6. Gouvernement du Québec. Le Développement; Rapport de la Commission d'enquête sur la santé et les Services Sociaux, CESBS, Claude Castonguay; Nepveu, G., Ed.; Éditeur Officiel: Quebec-City, QC, Canada, 1971.

7. Nirje, B. The Basis and Logic of the Normalization Principle. Aust. N. Z. J. Dev. Disabil. 1985, 11, $65-68$. [CrossRef]

8. United Nations. Declaration of the Rights of Handicapped Persons; United Nations: New York, NY, USA, 1975.

9. Wolfensberger, W.; Nirje, B. The Principles of Normalization in Human Services; National Institute on Mental Retardation: Toronto, ON, Canada, 1972.

10. De Jong, G. Independent living: From social movement to analytic paradigm. Arch. Phys. Med. Rehabil. 1979, 60, 435-446.

11. Woodhill, G. Independent Living and Participation in Research: A Critical Analysis; Centre for Independent Living: Toronto, ON, Canada, 1992.

12. Government of Quebec. The Act to Secure the Handicapped Persons in the Exercise of Their Rights; Government of Quebec: Quebec City, QC, Canada, 1978.

13. Government of Quebec. The Act to Secure the Handicapped Persons in the Exercise of Their Rights in a View to Achieving Social, School and Workplace Integration; Government of Quebec: Quebec City, QC, Canada, 2005.

14. Duckworth, D. The Classification and Measurement of Disablement; Department of Health and Social Security, Social Research Branch: London, UK, 1983. 
15. Nagi, S.Z. Some conceptual issues in disability and rehabilitation. In Sociology and Rehabilitation; Sussman, M.B., Ed.; American Sociological Association: Washington, DC, USA, 1965; pp. 100-113.

16. Nagi, S.Z. An Epidemiology of Disability among Adults in the United States. Milbank Mem. Fund Q. Health Soc. 1976, 54, 439-467. [CrossRef] [PubMed]

17. Wood, P.H.N. Classification of Impairments and Handicaps; ref. WHO/ICD9/REV"CONF/75.13; WHO: Geneva, Switzerland, 1975.

18. Wood, P.H.N.; Badley, E.M. Settling disablement in perspective. Int. Rehabil. Med. 1978, 1, 32-37. [CrossRef]

19. World Health Organisation. International Classification of Impairments, Disabilities and Handicaps; WHO: Geneva, Switzerland, 1980.

20. Joubert, P.L.; Lemay, L.; Bernard, L.; Fillion, R. Un Modèle Régional pour la Planification de Services Socio-sanitaires en Réadaptation; Direction des Services à la Clientèle du Centre Hospitalier de l'Université Laval: Quebec City, QC, Canada, 1980.

21. Joubert, P.; Fillion, R. L'influence des conditions ambiantes sur la construction du handicap: Pratiques québécoises en réadaptation. Santé Mentale au Canada 1981, 29.

22. Fougeyrollas, P. Le processus de production culturelle du handicap. Contextes Socio-historiques du Développement des Connaissances dans le Champ des Différences Corporelles et Fonctionnelles; CQCDIH-SCCIDIH: Lac-Saint-Charles, Quebec City, QC, Canada, 1995.

23. Fougeyrollas, P. La funambule, le fil et la toile. Transformations Réciproques $d u$ sens du Handicap; Presses de l'Université Laval: Quebec City, QC, Canada, 2010.

24. Wood, P.H.N. Origins of the ICIDH; ICIDH International Network: Quebec-City, QC, Canada, 1988; Volume 2.

25. OPHQ. On Equal Terms. The Social Integration of Handicapped Persons; A Challenge for Everyone; Publications du Québec: Drummondville, QC, Canada, 1984; 350p.

26. Oliver, M. The Politics of Disablement; MacMillan Press Ltd.: London, UK, 1990.

27. World Health Organization. International Classification of Functioning, Disability and Health; World Health Organization: Geneva, Switzerland, 2001.

28. Fougeyrollas, P.; St-Michel, G.; Bergeron, H.; Cloutier, R. The Disability Creation Process: Analysis of the Consultation, New Full Proposals; International Network ICIDH; Quebec Committee and Canadian Society on ICIDH: Quebec City, QC, Canada, 1991; Volume 4, pp. 8-37.

29. Fougeyrollas, P.; Bergeron, H.; Cloutier, R.; St.Michel, G.; Côté, J. Quebec Classification: Disability Creation Process; Updated 2016; INDCP: Quebec City, QC, Canada, 1999.

30. Fougeyrollas, P.; Charrier, F. Modèle du Processus de production du handicap. In Kinésithérapie-Médecine Physique-Réadaptation; EMC: Saint Paul, MN, USA, 2013; Volume 9, pp. 1-8.

31. Canadian Society on ICIDH. Canadian and international evolution of conceptual definitions related to persons with disabilities: Critical analysis, issues and perspectives. Int. Netw. ICIDH Environ. Factors 1998, 9, 2-3.

32. Ravaud, J.-F.; Fougeyrollas, P. Le concept de handicap et les classifications internationales. La convergence progressive des positions franco-québécoises. Santé Société et Solidarité. 2005, 2, 13-27. [CrossRef]

33. Badley, E.M. Enhancing the conceptual clarity of the activity and participation components of the International Classification of Functioning, Disability and Health. Soc. Sci. Med. 2008, 66, 2335-2345. [CrossRef] [PubMed]

34. Whiteneck, G.G.; Dijkers, M.P. Measuring difficult to measure constructs: Participation and environmental factors. Arch. Phys. Med. Rehabil. 2009, 90 (Suppl. 11), 22-35. [CrossRef] [PubMed]

35. Imrie, R. Demystifying disability: A review of the ICF. Sociol. Health Illn. 2004, 26, 287-305. [CrossRef] [PubMed]

36. Levasseur, M.; Desrosiers, J.; St-Cyr, T.D. Comparing the Disability Creation Process and the International Classification of Functioning, Disability and Health. Can. J. Occup. Ther. 2007, 74, 233-242. [CrossRef] [PubMed]

37. OPHQ. Guide Pour la Rédaction des Plans D'action; OPHQ: Drummonville, QC, Canada, 2011; 90p.

38. Fougeyrollas, P.; Fiset, D.; Boucher, N.; Gascon, H.; Morales, E.; Philibert, M.; Charrier, F. Handicap, environnement et droits humains. Du concept d'accès à sa mesure. In Développement Humain, Handicap et Changement Social; Numéro Hors-série; Collection Espace Participation Sociale; RIPPH: Quebec City, QC, Canada, 2015.

39. United Nations. Convention on the Rights of Persons with Disabilities; United Nations: New York, NY, USA, 2006.

40. OPHQ. Equals in every respect. In Because the Rights Are Meant to Be Exercised; Quebec Government: Quebec City, QC, Canada, 2009. 
41. OPHQ. Mise en œuvre de la politique gouvernementale À part entière: Pour un exercice effectif du droit à l'égalité; Bilan Annuel 2012-2013. Direction de l'évaluation, de la recherche et de la Communication; Quebec Government: Quebec City, QC, Canada, 2015; 210p.

42. Boucher, N.; Vincent, P.; Geiser, P.; Fougeyrollas, P. Participation des personnes en situations de handicap à la gouvernance locale: Présentation d'un projet visant à mesurer l'impact des stratégies de développement local inclusif. Alter 2015, 9, 51-63. [CrossRef]

43. Boucher, N.; Fougeyrollas, P.; Beaudouin, R.; Hazard, D.; Vincent, P. New Practical Guide for Planning and Evaluating to Promote the Rights of Persons with Disabilities; INDCP: Quebec City, QC, Canada, 2017.

(C) 2018 by the authors. Licensee MDPI, Basel, Switzerland. This article is an open access article distributed under the terms and conditions of the Creative Commons Attribution (CC BY) license (http://creativecommons.org/licenses/by/4.0/). 